\title{
Kaolin Geopolymer as Precursor to Ceramic Formation
}

\author{
Nur Ain Jaya ${ }^{1, *}$, Mohd Mustafa Al Bakri Abdullah ${ }^{2}$, Che Mohd Ruzaidi Ghazali, ${ }^{1,2}$, \\ Mohammed Hussain ${ }^{3}$, Kamarudin Hussin ${ }^{1,2}$, and Romisuhani Ahmad ${ }^{1}$ \\ ${ }^{1}$ Center of Excellence Geopolymer and Green Technology, School of Materials Engineering, \\ Universiti Malaysia Perlis (UniMAP), 01000, P.O Box 77, D/A Pejabat Pos Besar, Kangar, Perlis, \\ Malaysia. \\ ${ }^{2}$ Faculty of Engineering Technology, Universiti Malaysia Perlis (UniMAP), 01000, P.O Box 77, D/A \\ Pejabat Pos Besar, Kangar, Perlis, Malaysia. \\ ${ }^{3}$ King Abdul Aziz City Science \& Technology (KACST), P.O. Box 6086, Riyadh 11442, Kingdom of \\ Saudi Arabia.
}

\begin{abstract}
This paper introduced the potential application of kaolin geopolymer as ceramic precursor. This is one of the alternatives to produce high strength ceramic at a slightly lower temperature. Upon sintering the conversion of geopolymer to ceramic occur. The kaolin used were characterized using XRF and has plate-like structure upon investigating through microstructural analysis. Geopolymer mixture is produced using $12 \mathrm{M} \mathrm{NaOH}$ molarity with the $\mathrm{Na}_{2} \mathrm{SiO}_{3} / \mathrm{NaOH}$ ratio of 0.24 . The sintering temperature used were ranging from $900{ }^{\circ} \mathrm{C}$ to $1200{ }^{\circ} \mathrm{C}$. The flexural strength showed the highest value of $88.47 \mathrm{MPa}$ when sintered at $1200^{\circ} \mathrm{C}$. The combination of geopolymerization and sintering has attributed to the strength increment as temperature increased. The density is observed to increase with increasing sintering temperature due to the appearance of the close pores in the structure. Sintering of the geopolymer resulted in the formation of liquid phase, which enables the joining of particles to produce dense microstructure.
\end{abstract}

\section{Introduction}

The research into geopolymers was led by the needs of new heat resistant materials after various catastrophic fires in France in 1970. Geopolymers are hard, inorganic and stable up to $1400{ }^{\circ} \mathrm{C}$ and non-inflammable [1]. Geopolymerization is carried out by putting the aluminosilicate materials in contact with the alkaline activator solution which produce the polymeric chain of Si-O-Al-O bonds [2]. Geopolymers are amorphous to semi-crystalline three-dimensional silico-aluminate materials synthesized at low temperature in a short time. However, with the increasing temperature crystalline phase begins to appear [3]. The geopolymeric materials are considered as polymer but also geopolymer. Hence, it transforms, polycondense and adopt a shape rapidly at low temperature while also hard,

\footnotetext{
* Corresponding author: nurainjaya@email.org
} 
weather resistant and can withstand high temperatures [4]. As a result of excellent properties, geopolymers have been investigated for potential application in refractory and insulating areas industries.

In geopolymerization, an activator such as alkaline solution aids in the dissolution process of raw material by dissolving the soluble amorphous content of aluminosilicate materials in the first step of the polymeric reaction to form geopolymer precursors [5]. In this study, sodium silicate and sodium hydroxide were used as alkaline activator. The molarity of sodium hydroxide were fixed at $12 \mathrm{M}$ because it provides sufficient alkalinity to activate the kaolin and released $\mathrm{Al}^{3+}$ and $\mathrm{Si}^{4+}$ ions to participate in a geopolymerization process [6]. Apart from geopolymerization component, sintering played an important role to produce geopolymer ceramic. Sintering can be defined as the thermally activated adhesion processes which produce the growth of contacts between particles and their coalescence [7]. Sintering close some of the open pores, and cause the water absorption rate to decrease while increase the strength produced [8]. Geopolymer technology can be used to produce high performance ceramics at a slightly lower temperature compared to normal ceramics such as kaolin. Over the years, kaolin has been a very important ingredient in ceramics industry. However, the use of kaolin in producing ceramics through the conventional method requires high temperature (up to $1400^{\circ} \mathrm{C}$ ) processing to obtain high performance.

Geopolymers are known to have inflammability at high temperature during sintering. Thus, their behaviour at elevated temperature exposure is becoming an interest. Earlier studies on the thermal behaviour of geopolymers includes high-temperature reactions, phase changes on melting and thermal expansion properties of sodium polysialates and potassium sialate geopolymers $[9,10]$. Later, their behaviour at elevated temperature in the means of mechanical properties is becoming an interest. The mechanical properties of geopolymers are said to improve greatly when exposed to elevated temperatures [11]. Several researchers studied on the thermal behaviour of geopolymers prepared from different sources such as metakaolin [12-15] and fly ash [16, 17]. Despite being used in refractory and high temperature applications, geopolymers is gaining interest as precursors to ceramic formation. Cesium based geopolymers often used to produce pollucite ceramic $[18,19]$ and potassium based geopolymers as precursor to leucite ceramic [20, 21]. However, limited research was founded on using kaolin as the source materials and sodium based geopolymers. This study has used kaolin as the source material to study the effect of sintering temperatures on the mechanical strength and microstructure evolution of the geopolymer ceramics formed.

\section{Experimental method}

\subsection{Materials}

Kaolin used in this study was supplied by Associated Kaolin Industries Malaysia as Si-Al sources materials. The chemical composition of kaolin was determined by X-ray fluorescence. The particle size distribution of aluminosilicate materials was obtained using a Malvern particle size analyser as the mean particle size $d(50)$ is $9.465 \mu$ m. Sodium hydroxide $(\mathrm{NaOH})$ powder used to be of caustic soda micropearls, $99 \%$ purity with brand name of Formosoda-P made in Taiwan. Sodium silicate $\left(\mathrm{Na}_{2} \mathrm{SiO}_{3}\right)$ solution was supplied by South Pacific Chemicals Industries Sdn. Bhd. Malaysia with a chemical composition of $30.1 \% \mathrm{SiO}_{2}, 9.4 \% \mathrm{Na}_{2} \mathrm{O}$ and $60.5 \% \mathrm{H}_{2} \mathrm{O}$. 


\subsection{Sample Preparation}

Distilled water was used to prepare $12 \mathrm{M} \mathrm{NaOH}$ in a volumetric flask. The alkaline activator solution was formed by mixing $\mathrm{Na}_{2} \mathrm{SiO}_{3}$ to $\mathrm{NaOH}$ solution at a ratio of 0.24 until a clear solution was obtained for 24 hours. In order to produce geopolymer paste, kaolin powder was mixed with the alkaline solution with 1.0 solids-to-liquid ratio. The mixture then were mixed well for a few minutes and poured into HDPE mould. The samples were put into the oven at $80{ }^{\circ} \mathrm{C}$ for 24 hours for the curing process. After that, the samples were taken out of the oven and were crushed using mechanical crusher to make it into powder. To obtain fine powder, the samples were sieved manually to pass 150 micron sieve. In order to produce geopolymer ceramic, the sieved powders were then compacted using uniaxial isostatic pressing at 4.5 tons for 2 minutes. The final green body was sintered in a high temperature furnace to $900{ }^{\circ} \mathrm{C}-1200{ }^{\circ} \mathrm{C}$ with $3 \mathrm{~h}$ soaking time and a cooling and heating rate of $5{ }^{\circ} \mathrm{C} / \mathrm{min}$. All samples were sintered on an alumina plate as it can withstand high temperature firing.

\subsection{Tests and Analysis Method}

The density of sintered samples was measured using the pycnometry (AccuPyc II $1340 \mathrm{He}$ pycnometer, Micromeritics, GA, USA). Flexural strength measurements of kaolin geopolymer ceramics were conducted on specimens ( $7 \mathrm{~mm}$ x $5 \mathrm{~mm}$ x $52 \mathrm{~mm}$ ) using a threepoint-bending fixture on an instron-500 tester, with a span length of $30 \mathrm{~mm}$ at a crosshead speed of $0.3 \mathrm{~mm} / \mathrm{min}$. A minimum of five samples for each group was subjected to flexural strength testing in accordance with ASTM C1161-02c [22]. Scanning electron microscopy (SEM) was used to study the microstructure of the raw kaolin and the effect of sintering temperatures on kaolin geopolymer ceramic.

\section{Results and discussion}

\subsection{Raw materials characterization}

Table 1 tabulates the chemical composition of raw kaolin obtained by $\mathrm{x}$-ray fluorescence (XRF) analysis. The main elements of kaolin were $\mathrm{SiO}_{2}$ and $\mathrm{Al}_{2} \mathrm{O}_{3}$ make up the $86.8 \mathrm{wt}$ \% of the total composition. The silica content contributes to the formation of Si-O-Si bonds, which responsible for the mechanical strength of the geopolymer. Traces of other compounds also can be found in kaolin such as potassium oxide $\left(\mathrm{K}_{2} \mathrm{O}\right)$, iron oxide $\left(\mathrm{Fe}_{2} \mathrm{O}_{3}\right)$, titanium oxide $\left(\mathrm{TiO}_{2}\right)$, zirconium oxide $\left(\mathrm{ZrO}_{2}\right)$ and manganese oxide $\left(\mathrm{MnO}_{2}\right)$. The alumina and silica were held together by van der Waals and hydrogen bonding indicated by the layered structure as shown in Figure 1.

Table 1. Chemical composition of kaolin as determined by XRF

\begin{tabular}{|c|c|}
\hline Chemical & Wt (\%) \\
\hline $\mathrm{SiO}_{2}$ & 54.4 \\
$\mathrm{Al}_{2} \mathrm{O}_{3}$ & 32.4 \\
$\mathrm{Fe}_{2} \mathrm{O}_{3}$ & 4.32 \\
$\mathrm{TiO}_{2}$ & 1.33 \\
$\mathrm{Na}_{2} \mathrm{O}$ & 0.30 \\
$\mathrm{ZrO}_{2}$ & 0.07 \\
$\mathrm{~K}_{2} \mathrm{O}$ & 5.58 \\
$\mathrm{MnO}_{2}$ & 0.10 \\
$\mathrm{LOI}$ & 1.74 \\
\hline
\end{tabular}




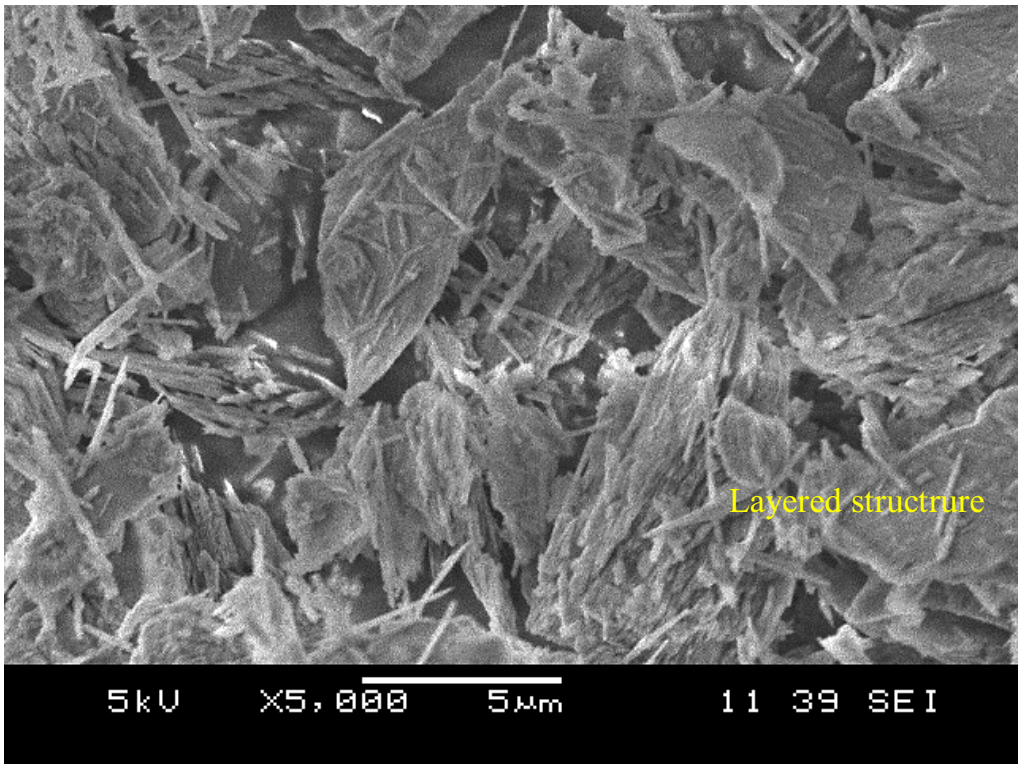

Fig. 4. Microstructure of raw kaolin

\subsection{Physical observation and density}

Figure 2 shows the physical observation of the kaolin geopolymer ceramic sintered at five different temperatures. All of the samples showed discolouration after sintering. The milky white colour of the samples sintered at 900 to $1200{ }^{\circ} \mathrm{C}$ resembles the colour of the pure kaolin used as the aluminosilicate source in this work. At lower temperature, the surface of the samples was rough and at higher temperature the surface become glazed. This can be observed when the samples were sintered at $1200{ }^{\circ} \mathrm{C}$ where it showed fully glazed surface which resembles glass. Increased the temperature to $1250{ }^{\circ} \mathrm{C}$ causes melting of the geopolymer which gives no definite shape. The colour also changed from milky white to brown due to the burn of geopolymer body. This indicates that temperature above $1200{ }^{\circ} \mathrm{C}$ is not suitable for sintering due to the exceeding melting point of KGC.

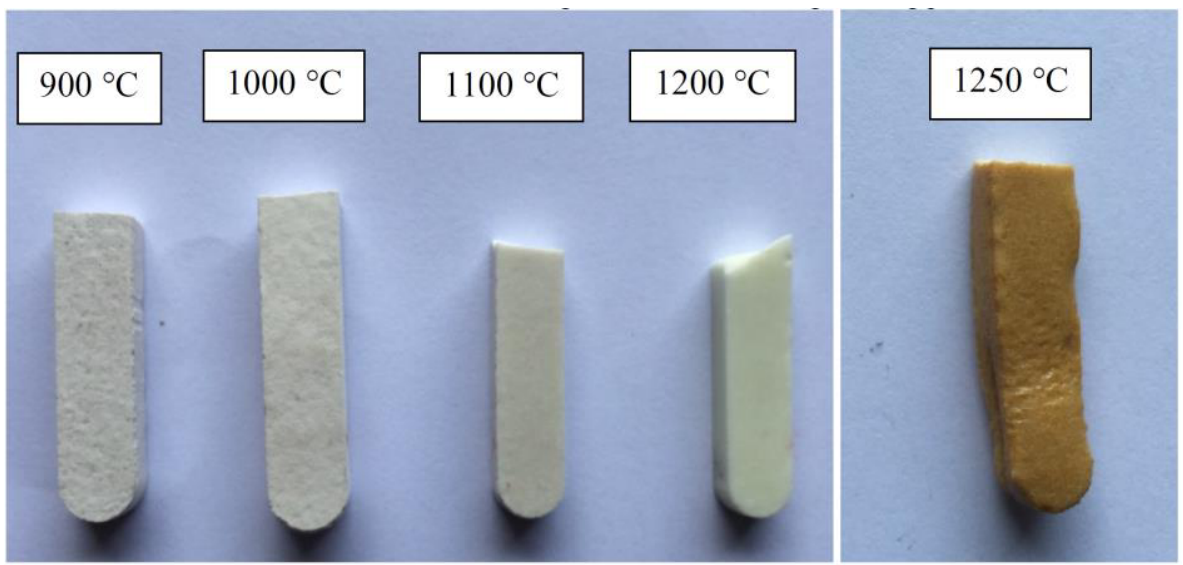

Fig. 5. Physical observation of KGC at different temperature 
Figure 2 shows the density for $\mathrm{KGC}$ at different sintering temperature. The density measured decreased with increasing sintering temperature. Sample sintered at $900{ }^{\circ} \mathrm{C}$ has the highest density of $2.69 \mathrm{~g} / \mathrm{cm}^{3}$ and samples sintered at $1200^{\circ} \mathrm{C}$ has the lowest density of $2.13 \mathrm{~g} / \mathrm{cm}^{3}$. The formation of large pores created at $1200{ }^{\circ} \mathrm{C}$ contributes to the lowest density. Sintering at low temperature cause the formation of small pores in geopolymer sample. However, increasing the sintering temperature linearly decreased the density due to the closed pores that present in the structure. The density of the sample with closed pores were measured with the density of the pores whilst for sample with open pores, the density measured were included the material density. This is true as at $900{ }^{\circ} \mathrm{C}$ the microstructure analysis showed the existence of open pores and showed a high density compared to samples sintered at $1200{ }^{\circ} \mathrm{C}$.

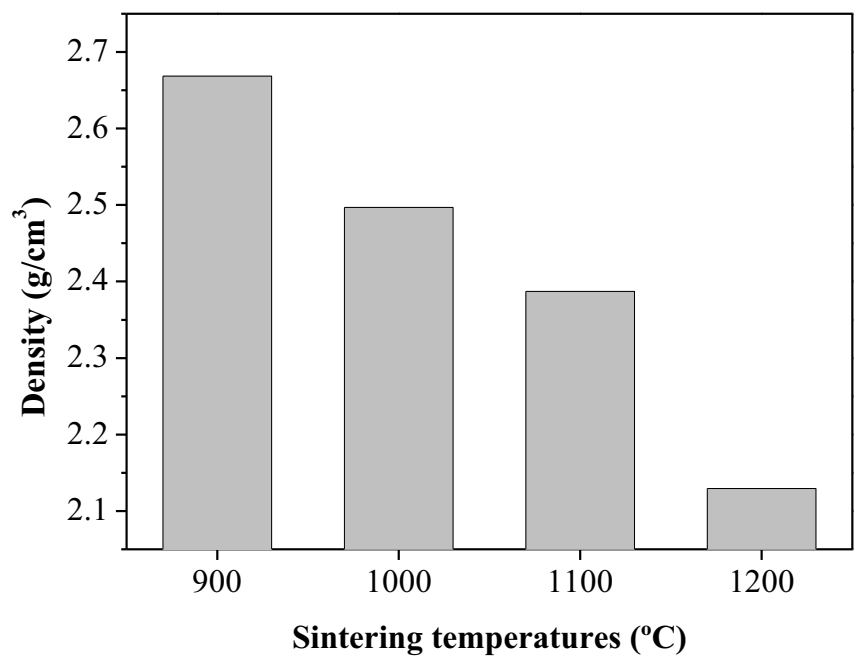

Fig. 6. Density of KGC with different sintering temperatures

\subsection{Flexural strength}

Figure 3 shows the flexural strength of kaolin geopolymer at four different sintering temperature. From the observation, increasing the sintering temperature increase the flexural strength. Heating the kaolin geopolymers to $900{ }^{\circ} \mathrm{C}$ resulted in the lowest flexural strength of $37.11 \mathrm{MPa}$. The low temperature of $900{ }^{\circ} \mathrm{C}$ is chosen based on Lee and Yeh [22] who reported the minimum firing temperature for clay-based ceramic is $900{ }^{\circ} \mathrm{C}$. This is due to the transformations of fine quartz particles above this temperature. The low temperature of $900{ }^{\circ} \mathrm{C}$ were not sufficient to bring the particle to diffuse well which cause low strength. Hence, produced low point of contact between the particles which later result in the formation of the open and interconnected pores as shown in Figure 5. The high strength achieved at $1200{ }^{\circ} \mathrm{C}$ is due to the particle that well diffused together to form larger sintered area to form a smooth geopolyer matrix. Kong et al. [23] have reported that the strength increment in geopolymer might be contributed by the combination of polymerization and sintering. This is due to the portions of unreacted particles in geopolymer body remained from the dissolution process. Exposure to temperature caused the sintering of these particles which leads to increasing strength by forming stronger bonds and countering the thermal damage at elevated temperatures [15]. The chemical 
composition of kaolin geopolymer ceramic determined by XRF in table 2 shows the increased percentage of $\mathrm{Na}$ which were assumed to play important role in the geopolymer bonding.

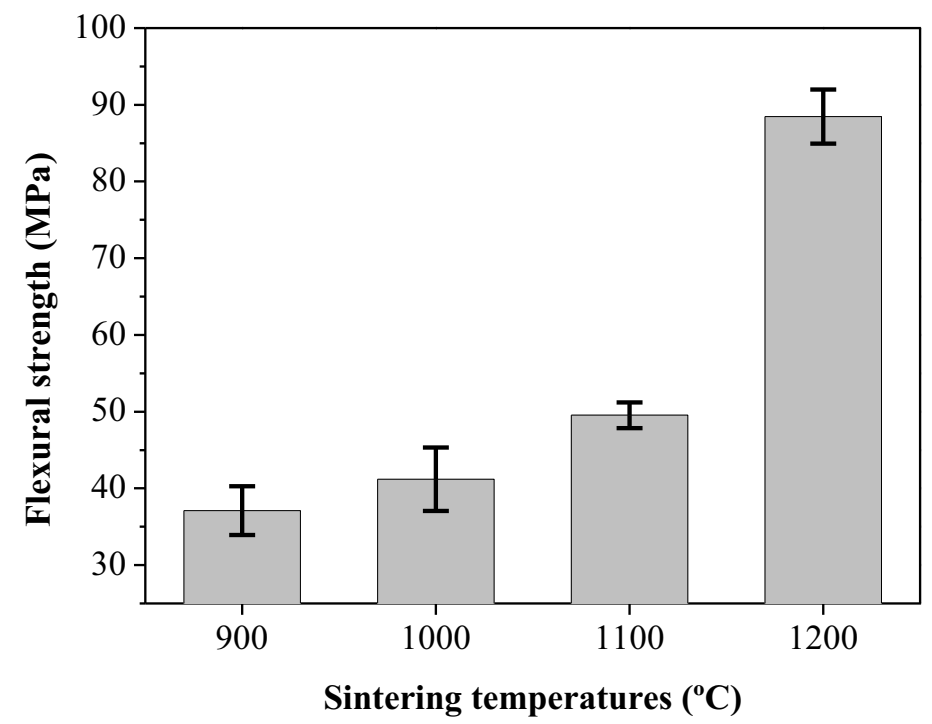

Fig. 7. Flexural strength of $\mathrm{KGC}$ at different sintering temperatures

Table 2. Chemical composition of kaolin geopolymer ceramic as determined by XRF

\begin{tabular}{|c|c|}
\hline Chemical & Wt (\%) \\
\hline $\mathrm{SiO}_{2}$ & 54.0 \\
$\mathrm{Al}_{2} \mathrm{O}_{3}$ & 27.7 \\
$\mathrm{Fe}_{2} \mathrm{O}_{3}$ & 5.04 \\
$\mathrm{TiO}_{2}$ & 1.23 \\
$\mathrm{Na}_{2} \mathrm{O}$ & 4.00 \\
$\mathrm{ZrO}_{2}$ & 0.10 \\
$\mathrm{~K}_{2} \mathrm{O}$ & 5.41 \\
$\mathrm{MnO}_{2}$ & 0.11 \\
$\mathrm{LOI}$ & 1.74 \\
\hline
\end{tabular}

\subsection{Microstructural analysis}

The microstructure of geopolymer ceramic after exposure to temperatures of $900{ }^{\circ} \mathrm{C}$, $1000{ }^{\circ} \mathrm{C}, 1100{ }^{\circ} \mathrm{C}$ and $1200{ }^{\circ} \mathrm{C}$ are shown Figure 5. The micrographs show the microstructure development of kaolin geopolymer sample as the temperature increases. The particles observed as plate which forming a layer-like structure at temperatures of $900{ }^{\circ} \mathrm{C}$ and $1000{ }^{\circ} \mathrm{C}$ which resembles the microstructure of pure kaolin but with smooth geopolymer matrix. The structure becomes more compacted in matrix form (smoother geopolymeric gel) at $1100{ }^{\circ} \mathrm{C}$ and $1200{ }^{\circ} \mathrm{C}$. The appearance of pores become well-shaped and homogeneously distributed as temperature rises indicate a better binding between kaolin and alkaline activator. Sintering the geopolymer resulted in the formation of liquid phase, which enables the joining of particles and the transformation of plate-like structure 
to dense microstructure [24]. This could explain the great advance in flexural strength. This study has shown that higher temperature aids in increasing the consolidation and facilitating a fairly uniform microstructure.
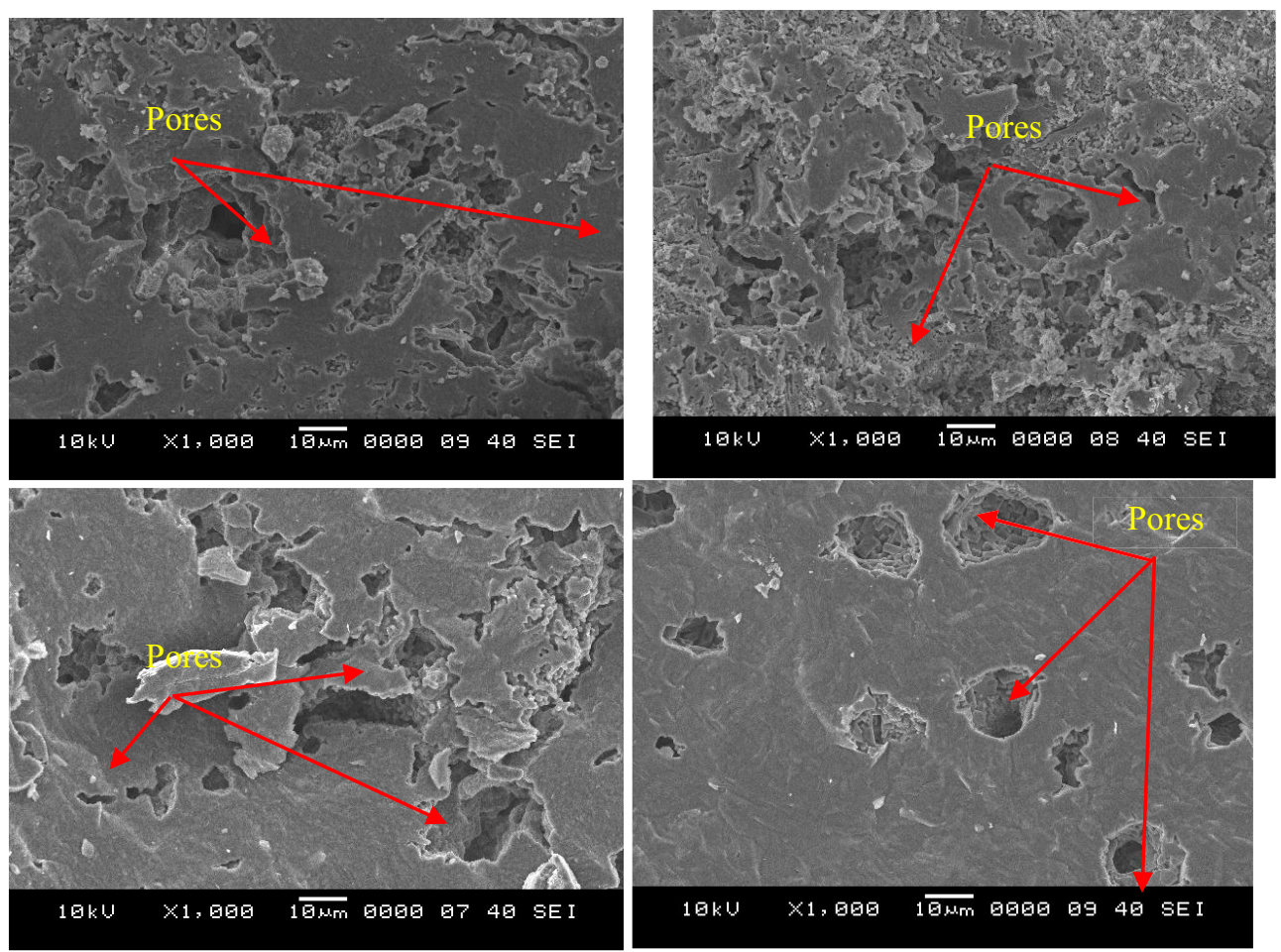

Fig. 8. Microstructure analysis of kaolin geopolymer ceramic with different sintering temperatures

\section{Conclusions}

This paper summarizes the work done on the synthesis of the geopolymer ceramics using kaolin as precursor material. The effect of sintering temperatures was studied on the final properties of kaolin geopolymer ceramics. Sintering temperature has a significant effect on the mechanical strength of the ceramics. From the results, it showed that sintering at 1200 ${ }^{\circ} \mathrm{C}$ gave highest flexural strength of $88.47 \mathrm{MPa}$. Increasing the sintering temperature increase the flexural strength of the ceramics. Sintering of the geopolymer enables the joining of particles and the transformation of plate-like kaolin structure to dense microstructure. Therefore, this indicates that high temperature were required to consolidate the geopolymer samples to achieve remarkable strength.

The authors would like to express gratitude KACST for funding this study through collaboration between KACST- UniMAP. 


\section{References}

1. J. Davidovits, J. Therm. Anal, 37, 1633 (1991)

2. D. Dimas, I. Giannopoulou, D. Panias, J. Mater. Sci., 44, 3719 (2009)

3. J.E. Oh, P.J.M. Monteiro, S.S. Jun, S. Choi, S.M. Clark, Cement Concrete Res., 40, 189 (2010)

4. J. Davidovits, J. Mater. Educ., 16, 91 (1994)

5. C.D. Atiş, E.B. Görür, O. Karahan, C. Bilim, S. İlkentapar, E. Luga, Constr. Build. Mater., 96, 673 (2015)

6. C.Y. Heah, H. Kamarudin, A.M.M.A. Bakri, M. Bnhussain, M. Luqman, I.K. Nizar, Int. J. Min. Met. Mater., 20, 313 (2013)

7. E. Olevsky, A. Molinari, Int. J. Plasticity, 16, 1 (2000)

8. X. Wang, Y. Jin, Z. Wang, R.B. Mahar, Y. Nie, J. Hazard. Mater., 160, 489 (2008)

9. $\quad$ V.F.F. Barbosa, K.J.D. MacKenzie, Mater. Ress. Bull., 38, 319 (2003)

10. V.F.F. Barbosa, K.J.D. Mackenzie, Mater. Lett., 57, 1477 (2003)

11. A.V. Riessen, W. Rickard, J. Sanjayan, Geopolymers: Structure, processing, properties and industrial applications (Woodhead Publishing Limited, UK, 2009)

12. P. Duxson, G.C. Lukey, J.S.J.v. Deventer, J. Non-Cryst. Solid, 352, 5541 (2006)

13. P. Duxson, G. C. Lukey, J.S.J.v. Deventer, J. Mater. Sci., 42, 3044 (2007)

14. P. Duxson, G.C. Lukey, J.S.J.v. Deventer, J. Non-Cryst. Solid, 353, 2186 (2007)

15. D.L.Y. Kong, J.G. Sanjayan, K. Sagoe-Crentsil, J. Mater. Sci., 43, 824 (2008)

16. T. Bakharev, Cement Concrete Res., 36, 1134 (2006)

17. J.G.S. Daniel L.Y. Kong, J.G. Sanjayan, Kwesi Sagoe-Crentsil, Cement Concrete Res., 37, 1583 (2007)

18. J. L. Bell, P. E. Driemeyer, W. M. Kriven, J. Am. Ceram. Soc., 92, 607 (2009)

19. P. He, D. Jia, M. Wang, Y. Zhou, Ceram. Int., 36, 2395 (2010)

20. J.L. Bell, P.E. Driemeyer, W.M. Kriven, J. Am. Ceram. Soc., 92, 607 (2009)

21. N. Xie, J. L. Bell, W. M. Kriven, J. Am. Ceram. Soc., 93, 2644 (2010)

22. V.G. Lee, T.H. Yeh, Mater. Sci. Eng., 485, 5 (2008)

23. D.L.Y. Kong, J.G. Sanjayan, K. Sagoe-Crentsil, Cement Concrete Res., 37, 1583 (2007)

24. B.K. Ngun, H. Mohamad, S.K. Sulaiman, M.Y.M. Sulaiman, T. Isobe, K. Okada, J. Ceram. Process. Res., 13, 547 (2012) 